\title{
Linear Growth Kinetics of Plaque-forming Streptococci in the Presence of Sucrose
}

\author{
By J. M. TANZER, W. I. WOOD* AND M. I. KRICHEVSKY \\ Environmental Mechanisms Section, National Institute of Dental Research, \\ National Institutes of Health, Bethesda, Maryland 200I4, U.S.A.
}

(Accepted for publication I7 June 1969)

SUMMARY

Growth of intact plaques of dextran-forming strain SL-I was linear both on a dry weight and DNA basis. Growth of broth cultures of dextran-forming strains SL-I and E-49 was linear with sucrose but exponential with other sugars; non dextran-forming strains $4 \mathrm{M} 4$ and JR8LG grew exponentially with all sugars tested. When dextranase was added to slowly growing cultures of dextran-forming strains SL-I and E-49, growth became rapid. Linear growth of strains SL-I and E-49 with sucrose is ascribable to extracellular dextran synthesized by the organisms.

\section{INTRODUCTION}

Certain streptococci cause dental caries and dental plaque formation in experimental animals (Fitzgerald \& Keyes, 1960). These cocci can be isolated, often in high numbers, from the plaques of experimental animals (Krasse \& Edwardsson, 1966) and humans (Carlsson, 1967; Krasse, Jordan, Edwardsson, Svensson \& Trell, 1968). The growth characteristics of plaque-forming streptococci have not been described, either as adhesive aggregates (plaque) or in broth culture.

Stralfors (1950) assumed that conditions in the mouth would favour rapid bacterial proliferation. From the data of Krasse (1954), Gibbons (1964) deduced that cariesconducive microbial plaque has only two or three growth cycles per day in vivo. Measurements of steady-state rates of faecal excretion of micro-organisms by conventional and gnotobiotic animals (Gibbons \& Kapsimalis, 1967) indirectly supported this deduction.

This report describes the in vitro growth of intact streptococcal plaque and of streptococci suspended in broth under conditions favourable for growth. Sucrose restricts these cells from growing exponentially. This effect is ascribable to dextran formation, a characteristic property of these organisms when grown with sucrose.

\section{METHODS}

Micro-organisms. Two strains of plaque-forming caries-conducive streptococci, SL-I and E-49, and two strains of non plaque-forming streptococci, 4M4 and JR8LG were studied. Implantation of SL-I, a human plaque isolate, or E-49, a streptomycin resistant variant of hamster plaque isolate HS-6 (Fitzgerald \& Keyes, I960), results in

* Present address: Cornell University, Ithaca, New York I4850. 
heavy plaque formation and caries in the hamster. The colonial characteristics of these strains resemble those described by Krasse (1966) for other caries-conducive streptococci of hamster or human origin. SL-I is similar antigenically (Kennedy, Sklair \& Bahn, I967) and biochemically (R. J. Fitzgerald, personal communication) to strain HS-6 described by Fitzgerald \& Keyes (1960). The in vitro plaque-forming characteristics of SL-I and E-49 have been described (McCabe, Keyes \& Howell, 1967; Tanzer \& McCabe, I968). Both strains form extracellular dextrans from sucrose (Gibbons, Berman, Knoettner \& Kapsimalis, 1966; Fitzgerald, Spinell \& Stoudt, I968) and produce dextran sucrase constitutively (J. M. Tanzer \& S. A. Robrish, unpublished data; R. J. Gibbons, personal communication). Both strains agglutinate in the presence of high molecular weight dextran and agglutinated cocci are dispersed by dextranase (Gibbons \& Fitzgerald, 1969). These strains are similar to those named Streptococcus mutans by Guggenheim \& Schroeder (1967) and Edwardsson (1968). Strain 4M4, isolated from the hamster, and strain JR8LG, isolated from the rat, are non plaque-forming, and presumably non dextran-forming. Strain 4M4 does not agglutinate in the presence of high molecular weight dextran (Gibbons \& Fitzgerald, I969). Tests of the pathogenicity of $4 \mathrm{M} 4$ and JR8LG have been negative (Jordan \& Keyes, 1966).

Growth of intact plaque in vitro. Cultures were maintained by passage at 10 to 14 day intervals in fluid thioglycollate medium (Baltimore Biological Laboratories, Baltimore, Md., U.S.A.) containing $20 \%(\mathrm{w} / \mathrm{v})$ horse meat infusion and excess $\mathrm{CaCO}_{3}$. Intact in vitro bacterial plaques were grown at $37^{\circ}$ as described by Tanzer \& McCabe (I968) using Io ml. broth (Jordan, Fitzgerald \& Bowler, 1960) supplemented with $50 \mathrm{mg}$. $\mathrm{Na}_{2} \mathrm{CO}_{3} / 1$. and $5 \%(\mathrm{w} / \mathrm{v})$ sucrose. Tubes of broth containing a cylindrical tared sterile glass rod $(5 \mathrm{~mm}$. dia.) immersed to a depth of $45 \mathrm{~mm}$. were inoculated with $0.2 \mathrm{ml}$. of SL-I and then stoppered with cotton. Each rod with adhering plaque was transferred at daily intervals to tubes of uninoculated broth for up to 7 days. Some of the glass rods were removed daily from the broth and dried to constant weight at $95^{\circ}$. The difference between the weight of the rod covered by dried plaque and that of the tared rod was taken as the dry weight of plaque. After weighing, the DNA content of the dried plaques was measured (see below). The DNA content of the broth tubes used for plaque growth also was assessed.

Growth of cells in broth culture. Cells were grown initially in broth (Jordan et al. 1960) supplemented with $50 \mathrm{mg}$. $\mathrm{Na}_{2} \mathrm{CO}_{3} / 1$. and containing an appropriate concentration of filter-sterilized sugar. After growth to stationary phase, I ml. was transferred to $40 \mathrm{ml}$. of the same broth contained in $200 \times 25 \mathrm{~mm}$. cotton-stoppered tubes. Growth was followed at $37^{\circ}$. After vigorous agitation, $\mathrm{I} \cdot 0 \mathrm{ml}$. samples were withdrawn periodically, their turbidity and $\mathrm{pH}$ measured, and DNA extracted and analysed.

In some experiments, 50 units of filter-sterilized dextranase were added $/ \mathrm{ml}$. broth; control tubes received boiled dextranase. Dextranase (Fitzgerald et al. 1968) was kindly supplied by Dr R. J. Fitzgerald (Dental Research Unit, V.A. Hospital, Miami, Florida, U.S.A.).

Analytical methods. The dry weight of intact plaques was evaluated using a semimicro analytical balance, maximum variation $\pm 0.05 \mathrm{mg}$. DNA was extracted by a slight modification of the method of Ogur \& Rosen (1950). Dried plaques were extracted for $30 \mathrm{~min}$. in $0.5 \mathrm{~N}-\mathrm{HClO}_{4}$ at $70^{\circ}$ (longer periods of extraction solubilized 
no additional DNA). To the culture tubes from which the plaque-coated glass rods were removed, $\mathrm{HClO}_{4}$ was added to $0.5 \mathrm{~N}$ and DNA was extracted by the same procedure. In the broth culture experiments, DNA was extracted by $0.5 \mathrm{~N}-\mathrm{HClO}_{4}$ from the material trapped on $0 \cdot 45 \mu$ pore diameter Millipore discs (Millipore Corporation, Bedford, Mass., U.S.A.) when samples of culture were filtered. DNA was analysed by the method of Burton (1956), using 2-deoxy-D-ribose standards (Sigma Chemical Co., St. Louis, Mo., U.S.A.) and expressed as deoxyribose. Turbidities of culture samples were assessed at $600 \mathrm{~m} \mu$ with a Model 300 microsample spectrophotometer (Gilford Instrument Laboratories, Oberlin, Ohio, U.S.A.), I cm. light path. $\mathrm{pH}$ values were measured using a standard laboratory combination electrode and $\mathrm{pH}$ meter. In all experiments Gram stains of smears were made as a check of purity.

\section{RESULTS}

Growth of intact plaque in vitro. Growth of plaque on glass rods was linear, both on a dry weight and deoxyribose content basis (Fig. I). Regression analysis of individual values of dry weight and deoxyribose shows that 98.3 and $96.7 \%$ of the respective variations are accounted for by the linear growth model. The mean rate of plaque growth on the rods was $6 \cdot 8 \mu \mathrm{g}$. dry weight $/ \mathrm{mm} .^{2} /$ day.

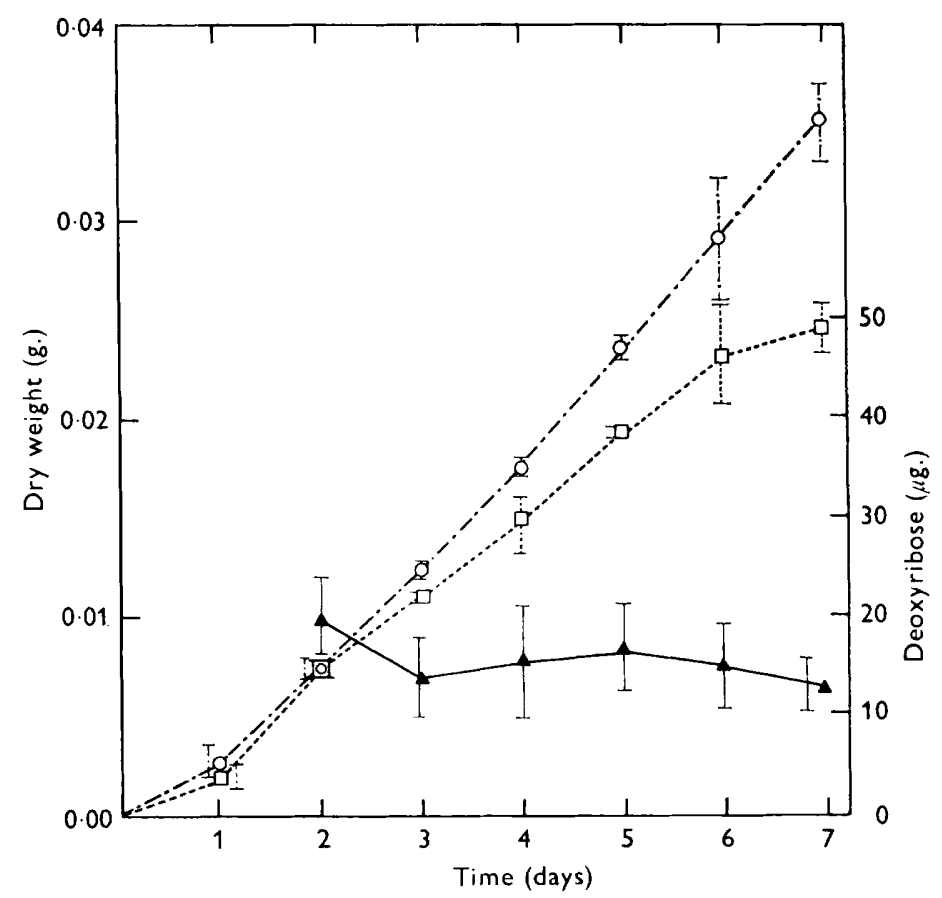

Fig. I. Growth of intact plaque of SL-I in vitro. Twenty-eight plaques were grown on glass rods in broth containing $5 \%$ sucrose. At daily intervals all but four rods were transferred to tubes of fresh broth. The dry weight $(O)$ and deoxyribose $(\square)$ content of the four plaques for each day were determined. Deoxyribose was determined in the spent broth tubes $(\boldsymbol{\Delta})$ used for each day's plaque growth after removal of the plaque-coated glass rod. Mean values \pm S.D. are plotted. 
The daily mean values of deoxyribose in the culture tubes, after the removal of the plaque-coated rods, were not different from each other except on day $2(p<0.05)$, when tested by analysis of variance. Possibly this difference was due to carry-over of non-adhering cells from the initial inoculum, since it was not seen on subsequent days.

Growth of cells suspended in broth culture. Linear rather than exponential growth of intact plaque was unexpected. To determine whether this character was due to geometrical limitation imposed by the glass rod supporting the plaque or whether it was due to some other factor, growth without the glass rod was studied, employing various sugars in the broth.

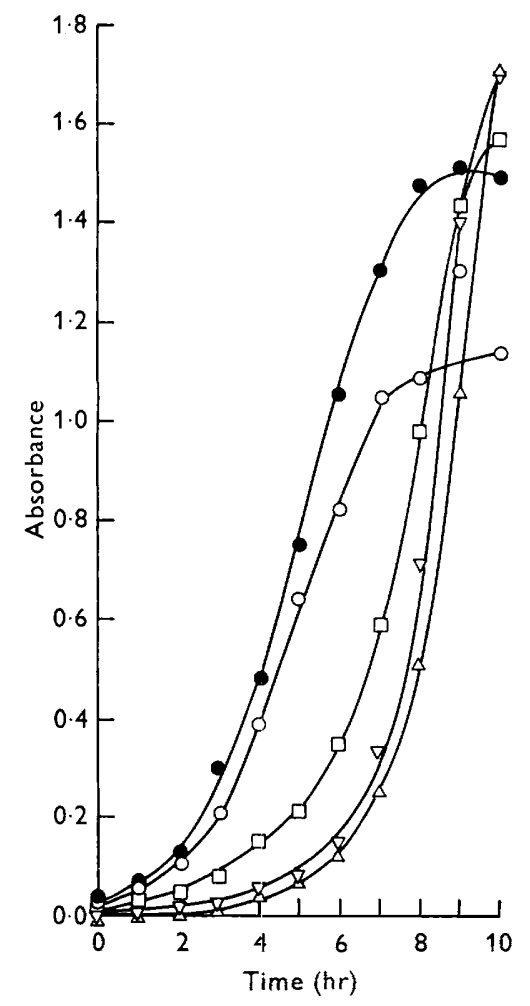

Fig. 2

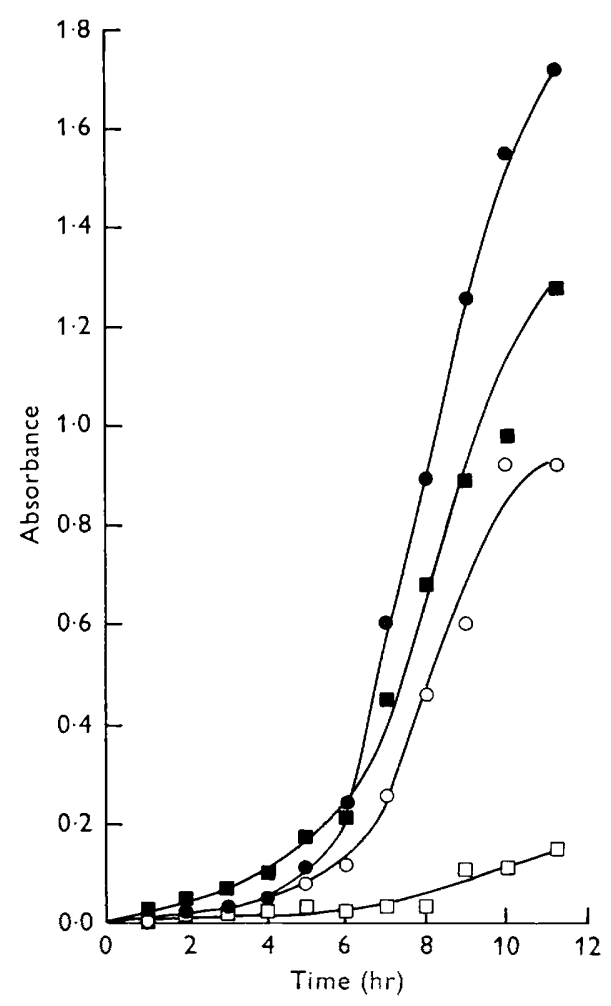

Fig. 3

Fig. 2. Plot of growth of SL-I in broth culture. Medium contained either 0.0I M-sucrose $(\bigcirc), 0.02 \mathrm{M}$-sucrose $(0), 0.02 \mathrm{M}$-fructose $(\square), 0.02 \mathrm{M}$-glucose $(\triangle)$, or $0.01 \mathrm{M}$-glucose and ०.OI M-fructose $(\nabla)$.

Fig. 3. Effect of dextranase upon the growth of SL-1 or E-49 in broth containing $0.02 \mathrm{M}-$ sucrose. Dextranase was added to the broth with the inocula as follows: SL-I without dextranase (O), with dextranase (O); E-49 without dextranase ( $\square$ ), with dextranase ( $\square$ ).

Gram stained smears of cultures from sucrose broth revealed clumping of cocci while smears of cultures from other sugars revealed discretely separated chains of cocci. Thus it was necessary to show that absorbance was a valid index of microbial mass, irrespective of the nature of sugar employed and over the wide range of absorbance values observed. When SL-I was grown in broth cultures containing either $0.02 \mathrm{M}-$ sucrose, fructose, glucose or $0.0 \mathrm{I} \mathrm{M}$-fructose $+0.0 \mathrm{I} \mathrm{M}$-glucose, the absorbance of the 
culture at $600 \mathrm{~m} \mu$ was highly correlated with the deoxyribose content of the culture $(r=0.982)$, over the range 0 to 1.8 absorbance and 0.2 to $5 \mu \mathrm{g}$. deoxyribose $/ \mathrm{ml}$. Accordingly, turbidity was used as an index of growth.

Growth of SL-I in broth containing $0.02 \mathrm{M}$-fructose, glucose, or fructose + glucose was exponential and gave high growth yields. Growth in sucrose, however, deviated from exponential behaviour (Fig. 2). Growth in 0.01 M-sucrose tended to be more rapid and gave higher yield than in $0.02 \mathrm{M}$-sucrose. Both appeared linear over most of

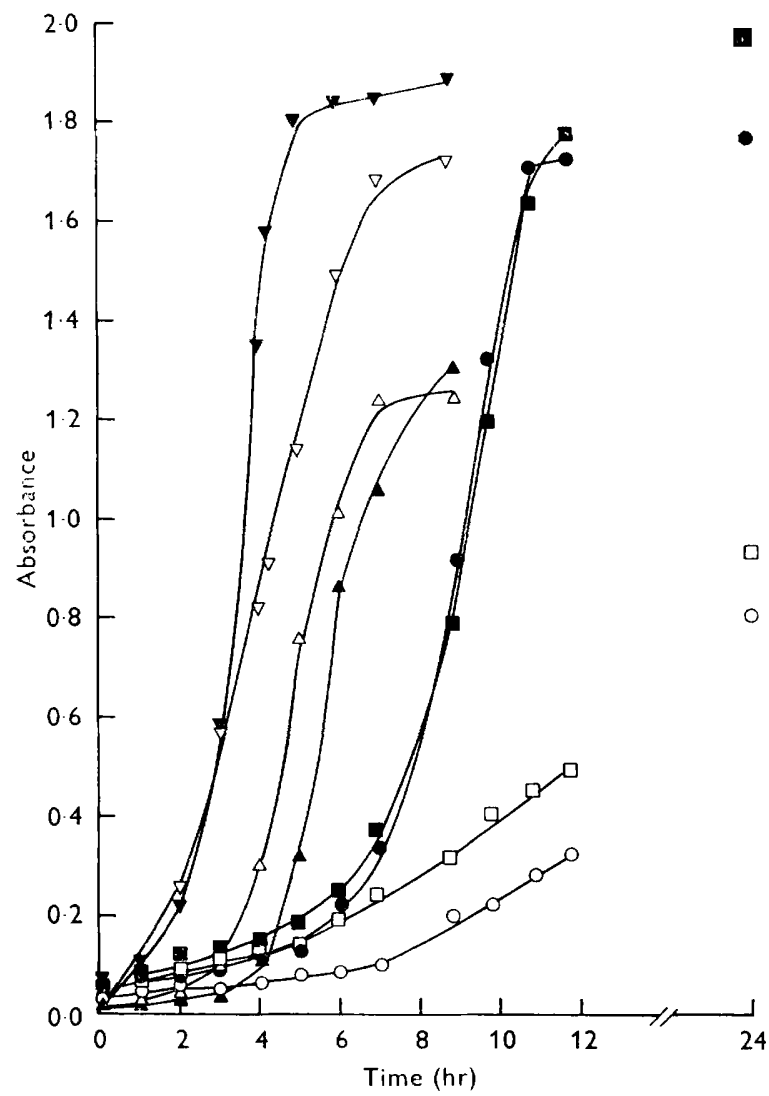

Fig. 4. Growth of dextran-forming strains SL-1 or E-49 and non dextran-forming strains JR8LG or 4M4 in broths containing various sugars. All sugars were at a concentration of $0.02 \mathrm{M}$. SL-I grown in broth containing glucose + fructose $(\bullet)$ or sucrose $(\bigcirc)$; E-49 grown in broth containing glucose + fructose ( $\square$ ) or sucrose ( $\square$ ); $4 \mathrm{M} 4$ grown in broth containing glucose + fructose $(\Delta)$ or sucrose $(\triangle)$; JR 8LG grown in broth containing glucose +fructose $(\nabla)$ or sucrose $(\nabla)$.

their range. The $\mathrm{pH}$ always fell more slowly in the sucrose-containing tubes than in others. In other experiments, cultures with less sucrose (e.g. $<0.005 \mathrm{M})$ showed a tendency to exponential growth while more sucrose (e.g. $>0.02 \mathrm{M}$ ) also showed growth restriction. Comparable concentrations of other sugars did not reveal any deviation from exponential growth or unexpected limitation of growth yield.

Throughout this paper linear plots will be presented. In all cases semilogarithmic plots revealed non-exponential growth whenever sucrose was in the culture medium. 
Formation of dextrans by plaque-forming caries-conducive streptococci depends on sucrose (Donahue, Kestenbaum \& King, 1966; Gibbons et al. 1966; Wood \& Critchely, I966; Dahlquist, Krasse, Olsson \& Gardell, 1967; Gibbons \& Banghart, 1967; Gibbons \& Banghart, 1968; Guggenheim \& Schroeder, 1967; Fitzgerald \& Jordan, 1968). Formation of extracellular dextran might therefore restrict the growth of plaque-forming streptococci.

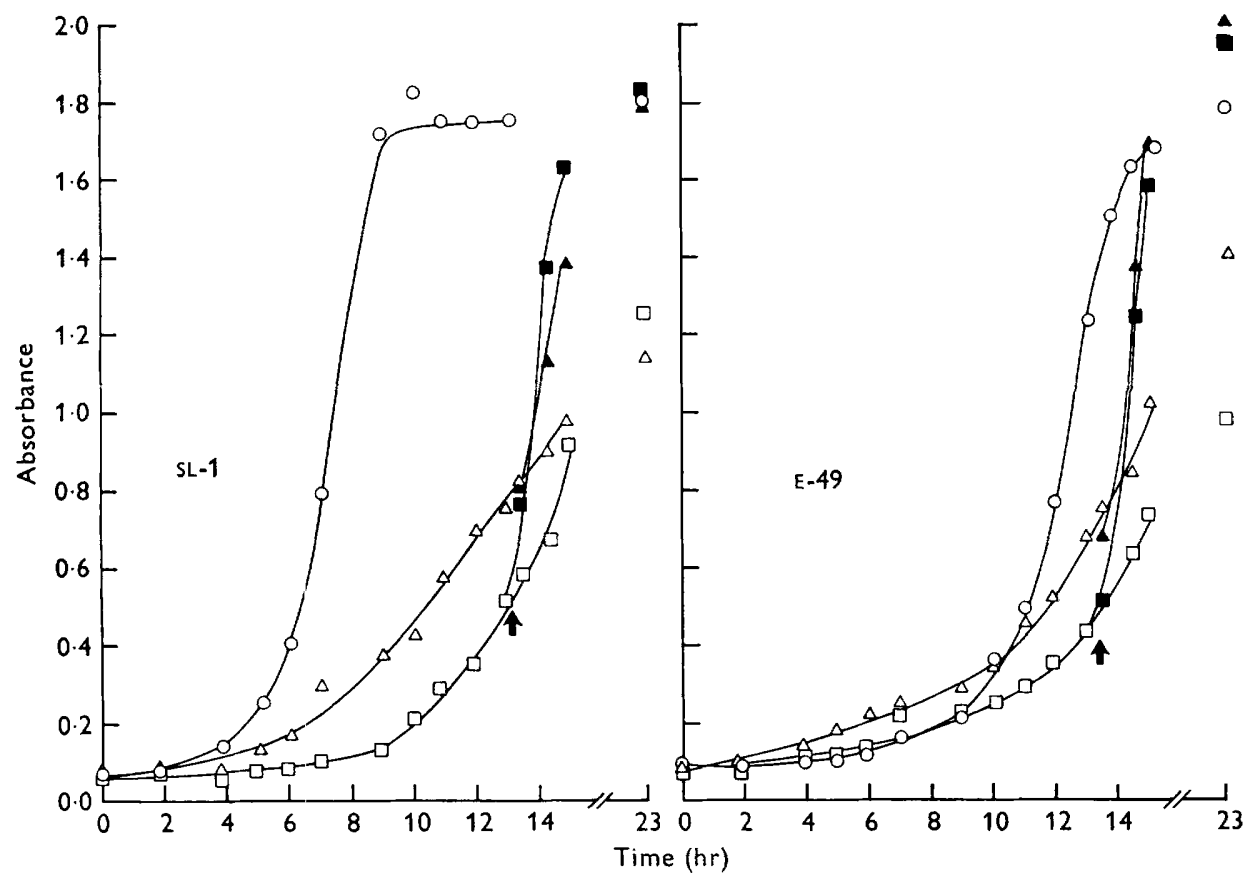

Fig. 5. Growth of either SL-I or E-49 before and after dextranase addition to broths containing various sugars. Arrows indicate the point of addition of either dextranase (closed symbols) or boiled dextranase (open symbols) to broths containing sucrose. The following symbols are employed: glucose + fructose $(0)$; glucose, fructose, sucrose and boiled dextranase $(\square)$; glucose, fructose, sucrose and active dextranase $(\boldsymbol{\square})$; sucrose and boiled dextranase $(\triangle)$; or sucrose and active dextranase $(\Delta)$. All sugars were initially present at $0.02 \mathrm{M}$. At $\mathrm{I} 5 \mathrm{hr}$ the culture of SL-I in broth containing glucose, fructose + sucrose ( $\square$ ) was shown by gramme staining to be impure. In all other growth experiments reported here cultures were judged by this criterion to be uncontaminated.

To test this hypothesis, SL-I or E-49 was grown in sucrose-containing broth to which dextranase preparation was added simultaneously. Growth was restricted when inactive dextranase was present (Fig. 3); both SL-I and E-49 grew poorly, with SL-I the better of the two. Growth of both strains was exponential with dextranase preparation and growth yields were higher. We later learned that the dextranase preparation also had substantial invertase activity (R. J. Fitzgerald, personal communication), so exponential growth in sucrose-containing broth might either be the result of a true dextranase effect or the result of presenting the cells with glucose and fructose produced by invertase activity.

To resolve this ambiguity two types of experiments were car ried out. In the first, non dextran-forming strains $4 \mathrm{M} 4$ and JR8LG were compared to dextran-forming 
strains SL-I and E-49 in either sucrose-containing broth or in broth containing equimolar amounts of glucose + fructose. Sucrose restricted growth only for the dextranforming strains; the other strains grew exponentially (Fig. 4). All strains grew exponentially with glucose + fructose.

The second experiment took advantage of the observation that the dextran-forming system is constitutive: this enzyme should function as long as sucrose is present, irrespective of the presence of other sugars. Strains SL-I and E-49 were grown in broths containing $(a)$ glucose + fructose, $(b)$ sucrose, or $(c)$ a mixture of all three sugars. Dextranase was added later during growth. Growth was restricted with the combination of sucrose, glucose and fructose as well as sucrose alone (Fig. 5). Thus the presence of substantial amounts of glucose and fructose, which would be produced by invertase activity, did not permit exponential growth so long as sucrose was present. When the sucrose-containing cultures were divided and dextranase preparation was added to half of each slowly growing culture, a period of rapid growth followed. Addition of boiled dextranase preparation to the remaining half of each culture produced no apparent increase of growth rate. Gram stained smears of cultures containing sucrose revealed clumps of cocci. After dextranase addition streptococci were seen in discrete chains.

\section{DISCUSSION}

Plaque-forming streptococcus SL-I adhering to a solid surface in vitro grew in a linear fashion. The proportion of DNA to the total dry mass of the plaque did not change, indicating that intact in vitro plaque probably does not change its composition grossly with time. The experiment did not test directly whether intact plaque growth within a $24 \mathrm{hr}$ period was linear or exponential. The restricted growth of plaque-forming streptococci in sucrose-containing broth without the presence of a glass rod, strongly indicates that growth on a solid surface during any part of a $24 \mathrm{hr}$ period is not exponential.

Growth of intact plaque in complex bacterial growth medium was slow: it required about $\mathrm{I} \cdot 9$ days for the dry mass of plaque to double. This contradicts the suggestion of Stralfors (1950) that plaque grows rapidly in the oral fluids and indicates that Gibbons's (1964) estimation of the rate of proliferation of bacterial plaques in vivo may be too high. In the medium employed in the present study the conditions for streptococcal proliferation are probably much better than those existing in the mouth at the surface of the tooth. Therefore, streptococcal plaque growth in vivo should be even slower than the rate in vitro. Unfortunately, direct determinations in vivo of the rate of plaque growth in bacterially well-defined plaques have not been reported.

Sucrose led to linear growth of plaque-forming strains SL-I and E-49 in broth culture. Hence, the linear growth observed for intact plaques was not due to geometrical limitations imposed by the solid surface on which plaque was growing. Formation of extracellular dextrans by SL-I and E-49 in the presence of sucrose appears to limit their growth because (I) non plaque-forming strains JR8LG and 4M4, which do not form dextrans from sucrose, grew exponentially with sucrose, (2) plaque-forming strains grew rapidly with sucrose after addition of dextranase. The invertase activity of the dextranase preparation was not relevant.

Growth restriction may result from a diffusion barrier imposed by extracellular dextran. However, linear growth cannot be explained by postulating a diffusion 
barrier surrounding individual cocci, since binary fission of such cells should produce exponential growth kinetics, although with a slower generation time. Because growth in the presence of sucrose is linear, the data suggest that the diffusion barrier exists around clumps of cells, i.e. microcolonies.

The authors wish to express their thanks to Mr Rickley Senning, Biometry Section, National Institute of Dental Research, National Institutes of Health, Bethesda, Maryland, U.S.A. for valuable assistance in statistical analysis of the data.

\section{REFERENCES}

BURTON, K. (1956). A study of the conditions and mechanism of the diphenylamine reaction for the colorimetric estimation of deoxyribonucleic acid. Biochem. J. 62, 315.

Carlsson, J. (1967). Presence of various types of non-haemolytic streptococci in dental plaque and in other sites of the oral cavity in man. Odont. Revy $18,55$.

Dahlquist, A., Krasse, B., Olsson, I. \& Gardell, S. (1967). Extracellular polysaccharides formed by caries-inducing streptococci. Helv. odont. Acta $\mathbf{~ I I}, \mathrm{I} 5$.

Donahue, J. J., Kestenbaum, R. C. \& King, W. J. (1966). The utilization of sugar by selected strains of oral streptococci. Int. Ass. Dent. Res. Abstracts, 44th General Meeting. Miami Beach, Fla. p. 52.

EDwARDSson, S. (1968). Characteristics of caries-inducing human streptococci resembling Streptococcus mutans. Archs oral Biol. r3, 637.

Fitzgerald, R. J. \& Jordan, H. V. (I968). Polysaccharide producing bacteria and caries. In: Art and Science of Dental Caries Research. Ed. by R. S. Harris, p. 79. New York: Academic Press.

FitzGerald, R. J. \& Keyes, P. H. (1960). Demonstration of the etiologic role of streptococci in experimental caries in the hamster. J. Am. dent. Ass. 6r, 9.

FitzGerald, R. J., Spinell, D. M., \& Stoudt, T. H. (I968). Enzymatic removal of artificial plaques. Archs oral Biol. 13, I25.

GibBons, R. J. (I964). Bacteriology of dental caries. J. dent. Res. 43, (Part I, Suppl.) I02 I.

GibBONS, R. J. \& BANGHART, S. (1967). Synthesis of extracellular dextran by cariogenic bacteria and its presence in human dental plaque. Archs oral Biol. 12, II.

GibBons, R. J. \& BANGHART, S. (1968). Variation in extracellular polysaccharide synthesis by cariogenic streptococci. Archs oral Biol. 13, 697.

GrbBons, R. J. \& FrtzGerald, R. J. (1969). Dextran induced agglutination of Streptococcus mutans and its potential in the formation of microbial dental plaques. J. Bact. 98, 34I.

GibBons, R. J. \& KAPSIMALIS, B. (1967). Estimates of the overall rate of growth of the intestinal microflora of hamsters, guinea pigs, and mice. J. Bact. 93, 5 IO.

GibBons, R. J., Berman, K. S., Knoettner, P. \& Kapsimalis, B. (1966). Dental caries and alveolar bone loss in gnotobiotic rats infected with capsule forming streptococci of human origin. Archs oral Biol. II, 549.

GugGENHEIM, B. \& SCHROEDER, H. E. (1967). Biochemical and morphological aspects of extracellular polysaccharides produced by cariogenic streptococci. Helv. odont. Acta II, I3I.

JoRDAN, H. V. \& KeYES, P. H. (1966). In vitro methods for the study of plaque formation and carious lesions. Archs oral Biol. II, 793.

Jordan, H. V., FitzGerald, R. J. \& Bowler, A. E. (1960). Inhibition of experimental caries by sodium metabisulfite and its effect on the growth and metabolism of selected bacteria. J. dent. Res. 39, II6.

Kennedy, A. E., SkLair, I. L. \& Bahn, A. N. (1967). Antibodies to the cariogenic streptococci in humans. Int. Ass. Dent. Res. Abstracts, 45th General Meeting. Washington, D.C. p. 138.

KRASSE, B. (1954). The proportional distribution of Streptococcus salivarius and other streptococci in various parts of the mouth. Odont. Revy 5, 203.

Krasse, B. (1966). Human streptococci and experimental caries in hamsters. Archs oral Biol. II, 429.

KRASSE, B. \& EdwardSSON, S. (1966). The proportional distribution of caries-inducing streptococci in various parts of the oral cavity of hamsters. Archs oral Biol. II, I I37. 
Krasse, B., Jordan, H. V., Edwardsson, S., SVensson, I. \& Trell, L. (I968). The occurrence of certain 'caries-inducing' streptococci in human dental plaque material. Archs oral Biol. 13, 91 I.

McCabe, R. M., Keyes, P. H. \& Howell, A., Jun. (1967). An in vivo method for assessing the plaque forming ability of oral bacteria. Archs oral Biol. I2, 1653 .

OGuR, M. \& Rosen, G. (1950). The nucleic acids of plant tissues. I. The extraction and estimation of desoxypentose nucleic acid and pentose nucleic acid. Archs Biochem. 25, 262.

Stralfors, A. (1950). Investigation into the bacterial chemistry of dental plaques. Odont. Tidskr. $\mathbf{5 8}$, 155.

TANZER, J. M. \& MCCABE, R. M. (1968). Selection of plaque-forming streptococci by the serial passage of wires through sucrose containing broth. Archs oral Biol. 13, I39.

WoOD, J. M. \& CRITCHelY, P. (I966). The extracellular polysaccharide produced from sucrose by a cariogenic streptococcus. Archs oral Biol. II, 1039. 